\title{
Sleep quality among adult patients with chronic dermatoses
}

\author{
Karolina Kaaz, Jacek C. Szepietowski, Łukasz Matusiak \\ Department of Dermatology, Venereology and Allergology, Wroclaw Medical University, Wroclaw, Poland \\ Adv Dermatol Allergol 2019; XXXVI (6): 659-666 \\ DOI: https://doi.org/10.5114/ada.2019.84007
}

\begin{abstract}
Chronic dermatoses, including atopic dermatitis, psoriasis, prurigo nodularis, chronic spontaneous urticaria and hidradenitis suppurativa, as well as accompanying subjective symptoms (itch and pain), have a great impact on patients' well-being. Skin plays an important role in the physiological sleep process. This review attempts to analyze the association between chronic dermatoses in adults and sleep quality in recent studies. Polysomnography and actigraphy are performed for the objective assessment of sleep quality. Questionnaire-based subjective evaluations of sleep quality, including the Pittsburgh Sleep Quality Index and Medical Outcomes Study Sleep Scale, are useful in clinical studies and clinical practice. Subjective symptoms such as itch and pain have an essential influence on sleep quality and general quality of life in patients with chronic skin diseases.
\end{abstract}

Key words: chronic dermatosis, adult, sleep, polysomnography, actigraphy, Pittsburgh Sleep Quality Index.

\section{Introduction}

Chronic skin diseases generally have a complex multifactorial pathogenesis which involves genetic predisposition, environmental factors and immune system hyperactivity [1]. Chronic dermatoses impair healthrelated quality of life $(\mathrm{Q} O \mathrm{~L})$ in affected patients, having an impact on multiple aspects of psychophysical functioning and patients' well-being. Sleep is a physiological, fundamental, active process that takes around one-third of humans' lives. It is regulated by two major processes homeostatic sleep drive and circadian system [2, 3]. Skin plays an important role in proper sleep activity, which includes control of thermoregulation, core body temperature, sleep onset, and awakenings during sleep.

Impaired sleep quality is associated with systemic diseases, e.g. chronic obstructive pulmonary disease (COPD) [4], obstructive sleep apnea and hypopnea syndrome (OSAHS) [5], heart failure [6, 7], cancers [8-11], lymphoma [12], systemic lupus erythematosus [13, 14], psoriatic arthritis [15] and sarcoidosis [16].

Moreover, chronic dermatoses (commonly pruritic and/or painful) including atopic dermatitis [17], psoriasis $[18,19]$, chronic spontaneous urticaria [20], prurigo nodularis [21], hidradenitis suppurativa [22], acne vulgaris [23] and lichen planus [24], may also substantially interfere with sleep quality, resulting in deterioration of general well-being.

Nocturnal itch has a complex pathophysiologic mechanism, but still it is unclear. Underlying mechanisms accountable for nocturnal itch include e.g. changing of skin barrier function (increasing of trans-epidermal water loss (TEWL) at night) [25], thermoregulation (e.g. regulation of core body temperature which is maximal early in the evening and minimal early in the morning) [26], circadian rhythms (the hypothalamus-pituitary-adrenal axis is responsible for corticosteroid level regulation; corticosteroid level is minimal during the evening and night, which is reflected in a diminished anti-inflammatory reaction) [27], melatonin (associated with the support of circadian rhythm and the sleep cycle as a regulatory hormone) [28] and disruption of the endogenous molecules involved in physiologic circadian rhythm (prostaglandins (PG) - PGD2 and PGE2, opioids and opioid receptors, nerve growth factor (NGF), interleukins and cytokines - IL-2, IL-8, IL-31, INF- $\gamma$ ) $[3,27]$.

Nocturnal itch is undoubtedly associated with chronic skin diseases mentioned above (i.e. atopic dermatitis, psoriasis, prurigo nodularis, chronic spontaneous urticaria and lichen planus), but also with lichen simplex chronicus and bullous pemphigoid, conditions with severe symptoms (e.g. erythroderma) [3, 27, 29]. Skin in-

Address for correspondence: Łukasz Matusiak, Department of Dermatology, Venereology and Allergology, Wroclaw Medical University, 1 Chałubińskiego St, 50-368 Wroclaw, Poland, phone: +48 7178422 86, fax: +48 7132709 42, e-mail: luke71@interia.pl

Received: 4.12.2018, accepted: 19.03.2019. 
festations (e.g. bed bugs, scabies, pediculosis, pinworms) may also be accompanied by nocturnal itch [3, 27]. Moreover, Lavery et al. [3] reported non-dermatological conditions associated with nocturnal pruritus, including chronic kidney and liver disease, hematopoietic disorders, substance abuse, neurological (e.g. brachioradial pruritus) and psychological disorders (e.g. depression, schizophrenia, stress, delusional ideation), and restless legs syndrome.

The aim of this study was to review the published studies that have investigated the association between chronic dermatological conditions and sleep quality in adult patients.

\section{Methods used to assess sleep quality}

\section{Subjective methods}

\section{Pittsburgh Sleep Quality Index}

The Pittsburgh Sleep Quality Index (PSQI) is a selfreported questionnaire which assesses sleep quality and disturbances over a 4-week time interval. The PSQI is used to evaluate seven domains of sleep quality: subjective sleep quality, sleep latency, sleep duration, habitual sleep efficiency, sleep disturbances, use of sleeping medication and daytime dysfunction. The questionnaire uses 14 questions based on a $0-3$ scale (where 3 indicates the most negative outcome) and 4 open-ended questions. PSQI scores range from 0 to 21 points. A global score of $\geq 5$ is a specific and sensitive indicator of poor sleep quality [30-32].

\section{The Medical Outcomes Study - Sleep Scale}

The Medical Outcomes Study Sleep Scale (MOS-SS) is a validated instrument with 12 self-reported questions on multiple facets of sleep quality and quantity within a 4-week period [33-35]. The average MOS-SS score in the general population has been estimated at 25.8. The questionnaire generates seven measures for sleep quality: sleep disturbance, snoring, awakening short of breath or with a headache, sleep adequacy, daytime somnolence, Sleep Problem Index I (SPI I) and Sleep Problem Index II (SPI II) [36]. Each of the 7 sleep-quality scores range from 0 to 100. Greater scores for the six domains indicate worse sleep quality, except for sleep adequacy, for which greater scores indicate better sleep quality [36].

\section{Objective methods}

\section{Actigraphy}

An actigraph is a small, wrist-worn device that tracks sleep-wake patterns (sleep latency, efficiency, and periods of awakening) by using activity-based monitoring. It has been validated to assess sleep parameters and highly correlates with polysomnography [37]. Actigraphy may be the preferred method of assessing sleep in der- matological patients because it reflects the home environment (can be performed at home), is easy to use, well accepted by patients and cost-effective, and assesses the most commonly affected sleep parameters in patients with AD (e.g. sleep disruption secondary to nocturnal awakenings and scratching) [17, 38].

\section{Polysomnography}

Polysomnography (PSG) consists of an electroencephalogram (EEG), an electrooculogram (EOG) and an electromyogram (EMG), which together make up the gold standard of sleep examinations. Using PSG has two major drawbacks - the discomfort of having multiple leads and equipment attached and the necessity to stay overnight at a sleep center [17].

\section{Atopic dermatitis}

The mean prevalence of atopic dermatitis (AD) in the general population ranges from $2.1 \%$ to $4.9 \%$ across countries [39]. The disease is characterized by erythema, lichenified lesions and is accompanied by severe itch, which is an essential symptom of AD. It negatively influences various aspects of AD patients' well-being [40]. Sleep quality may be significantly disturbed in $A D$ patients. A higher prevalence of sleep disturbance was reported in adults with AD compared to controls [17]. Five reviewed studies used the PSQI questionnaire [37, 41-44] one of which also used actigraphy [42], and one study used actigraphy and polysomnography in addition to PSQI [43]. Two additional studies were based only on actigraphy $[38,45]$. The achieved mean PSQI score ranged from 7.0 to 8.5 points across the studies [37, 41, 42, 44] (Figure 1), and was significantly higher compared to controls $(p<0.01)[42,44]$. Moreover, PSQI scores significantly correlated with QoL assessed by the Dermatology Life Quality Index (DLQI) [37, 41] and AD severity [41]. Bender et al. [42] established a significant influence on subjective sleep quality and daytime dysfunction domains. Nonetheless, a significant impact of all domains of the PSQI among AD patients was also reported [44]. Moreover, the study by Bender et al. [43] revealed moderately strong correlations between actigraphy score and both PSG scores (sleep efficiency, sleep latency) and the scratching index. Increased itch and scratching during the night [38] seem to play a significant role as factors negatively affecting patients' sleep. Yano et al. [41] suggested that mood problems may also impair the quality of sleep. Detailed data are shown in Table 1 [37, 38, 41-45].

\section{Plaque psoriasis}

The average prevalence of psoriasis (Ps) in adults is assessed as 1-3\% worldwide [46]. Skin lesions in Ps are typically scaly plaques covering the scalp, elbows and knees, 


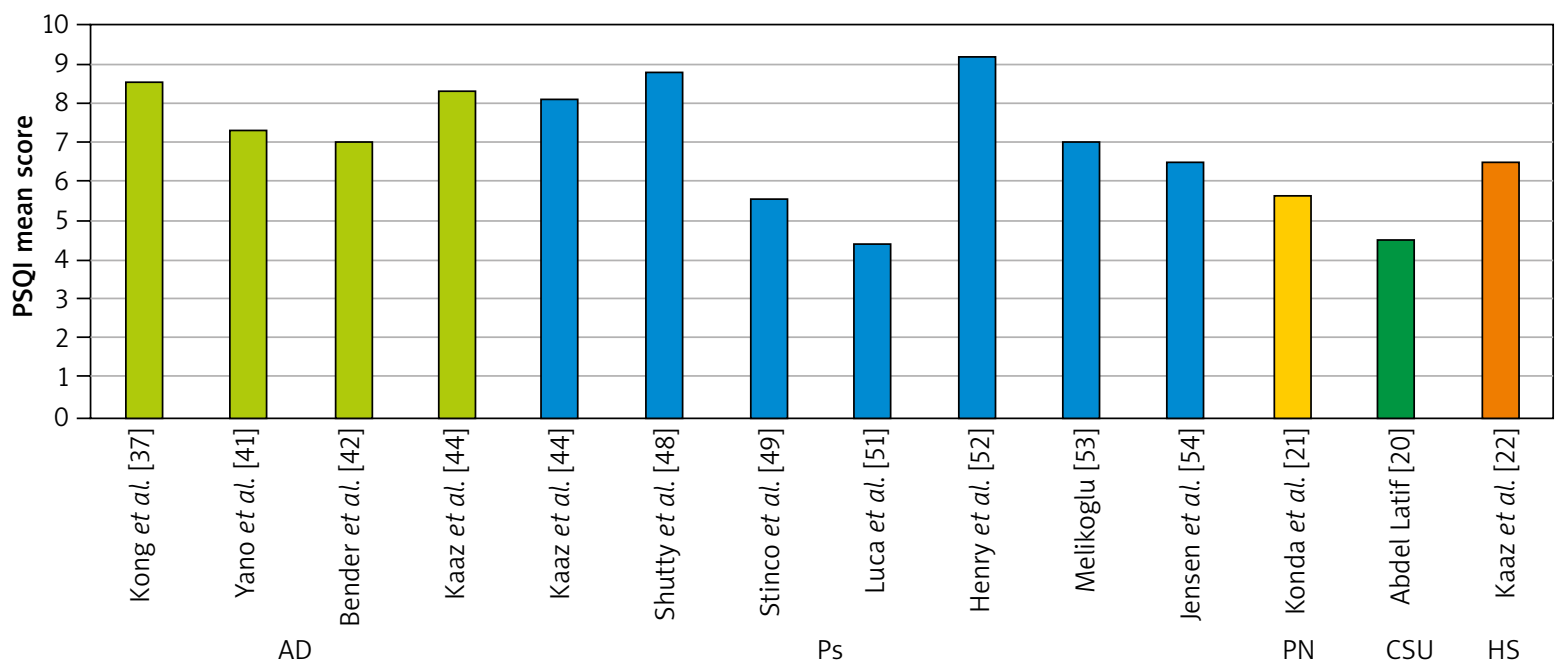

$A D$ - atopic dermatitis, $P S$ - psoriasis, $P N$ - prurigo nodularis, CSU - chronic spontaneous urticaria, HS - hidradenitis suppurativa.

Figure 1. PSQI mean scores among patients with chronic skin diseases

Table 1. Assessment studies of sleep quality among atopic dermatitis patients

\begin{tabular}{|c|c|c|c|c|}
\hline Study & Study design & $\begin{array}{l}\text { Measure of sleep } \\
\text { quality }\end{array}$ & Participants & Selected results \\
\hline $\begin{array}{l}\text { Bender et al., } \\
2003[42]\end{array}$ & $\begin{array}{l}\text { Case-control } \\
\text { study }\end{array}$ & $\begin{array}{c}\text { PSQI } \\
\text { Actigraphy }\end{array}$ & $\begin{array}{l}14 \text { AD patients vs. } \\
14 \text { controls }\end{array}$ & $\begin{array}{l}\text { PSQI mean scores: AD } 7.0 \pm 0.75 \text { points, control } \\
3.42 \pm 0.81 \text { points }(p<0.01)\end{array}$ \\
\hline $\begin{array}{l}\text { Bender et al., } \\
2008[43]\end{array}$ & $\begin{array}{l}\text { Uncontrolled } \\
\text { clinical study }\end{array}$ & $\begin{array}{l}\text { PSQI } \\
\text { Polysomnography } \\
\text { Actigraphy }\end{array}$ & $20 \mathrm{AD}$ patients & $\begin{array}{l}\text { PSQI mean score - data not shown. } \\
\text { Moderately strong correlations between actigraphy } \\
\text { scores and both the scratching index and } \\
\text { polysomnography scores, which included sleep latency, } \\
\text { sleep efficiency, and stage-2 sleep, were revealed }\end{array}$ \\
\hline $\begin{array}{l}\text { Yano et al. } \\
2013[41]\end{array}$ & $\begin{array}{l}\text { Uncontrolled } \\
\text { clinical study }\end{array}$ & PSQI & 112 AD patients & $\begin{array}{c}\text { PSQI mean score: } 7.3 \pm 2.8 \text { points. PSQI score was } \\
\text { significantly associated with DLQI }(r=0.43, p<0.001) \\
\text { and with SCORAD }(r=0.33, p<0.001)\end{array}$ \\
\hline $\begin{array}{l}\text { Kong et al., } \\
2016 \text { [37] }\end{array}$ & $\begin{array}{l}\text { Uncontrolled } \\
\text { clinical study }\end{array}$ & PSQI & $50 \mathrm{AD}$ patients & $\begin{array}{l}\text { PSQI mean score: } 8.51 \pm 7.32 \text { points. } \\
\text { PSQI scores significantly correlated with DLQI }(p=0.04)\end{array}$ \\
\hline $\begin{array}{l}\text { Kaaz et al., } \\
2018[44]\end{array}$ & $\begin{array}{l}\text { Case-control } \\
\text { study }\end{array}$ & PSQI & $\begin{array}{l}100 \text { AD patients vs. } \\
50 \text { controls }\end{array}$ & $\begin{array}{l}\text { PSQI mean scores: AD patients } 8.3 \pm 4.2 \text { points, controls } \\
3.1 \pm 1.9 \text { points }(p<0.0001)\end{array}$ \\
\hline $\begin{array}{l}\text { Bringhurst et al., } \\
2004[45]\end{array}$ & $\begin{array}{l}\text { Case-control } \\
\text { study }\end{array}$ & Actigraphy & $\begin{array}{l}15 \text { AD patients vs. } \\
30 \text { controls }\end{array}$ & $\begin{array}{l}\text { SCORAD score correlated with actigraphy activity score } \\
\text { (per hour) }(p<0.05)\end{array}$ \\
\hline $\begin{array}{l}\text { Sandoval et al., } \\
2014[38]\end{array}$ & $\begin{array}{l}\text { Uncontrolled } \\
\text { clinical study }\end{array}$ & $\begin{array}{l}\text { Actigraphy } \\
14 \text { days using } \\
\text { wrist actigraphy } \\
\text { monitors }\end{array}$ & 10 AD patients & $\begin{array}{c}\text { AD severity positively correlated with sleep } \\
\text { disturbances }\end{array}$ \\
\hline
\end{tabular}

AD - atopic dermatitis, PSQI - Pittsburgh Sleep Quality Index, SCORAD - SCORing of Atopic Dermatitis.

but nails and any other skin areas can also be affected [47]. Psoriasis is associated with significant medical and psychological morbidity with a great impact on patients' well-being. Sleep disturbance seems to be a common Psrelated problem in affected patients [18]. Eight reviewed studies were based on the PSQI questionnaire [44, 48-54], with six of them being case-control investigations [44, 48-
50, 53, 54]. The mean PSQI scores ranged from 4.4 to 9.2 points (Figure 1) [44, 48, 49, 51-53], and were significantly higher compared to controls $(p<0.01)$ (Table 2) [44, 48, 53, 54]. In contrast to studies listed above, Stinco et al. [49] did not observe a link between psoriasis and poor sleep quality. In published data among Ps patients, a significant influence on subjective sleep quality [50, 53], daytime 
Table 2. Assessment studies of sleep quality among plaque psoriasis patients

\begin{tabular}{|c|c|c|c|c|}
\hline Study & Study design & $\begin{array}{l}\text { Measure of } \\
\text { sleep quality }\end{array}$ & Participants & Selected results \\
\hline $\begin{array}{l}\text { Strober et al., } \\
2012[36]\end{array}$ & Clinical trial & $\begin{array}{c}\text { MOS-SS } \\
\text { SPI I and SPI II }\end{array}$ & 152 Ps patients & $\begin{array}{l}\text { MOS-SS scores: } \\
\text { - SPI I mean score } 34.1 \pm 17.4 \text { points } \\
\text { - SPI II mean score } 35.1 \pm 17.4 \text { points } \\
\text { Adalimumab treatment improved sleep outcomes of Ps } \\
\text { patients }\end{array}$ \\
\hline $\begin{array}{l}\text { Shutty et al., } \\
2013[48]\end{array}$ & $\begin{array}{l}\text { Case-control } \\
\text { study }\end{array}$ & PSQI & $\begin{array}{l}35 \text { Ps patients } \\
\text { vs. } 44 \text { controls }\end{array}$ & $\begin{array}{l}\text { PSQI mean scores: Ps patients } 8.8 \pm 4.4 \text { points, controls } \\
6.3 \pm 4.4 \text { points }(p=0.008)\end{array}$ \\
\hline $\begin{array}{l}\text { Stinco et al., } \\
2013[49]\end{array}$ & $\begin{array}{l}\text { Case-control } \\
\text { study }\end{array}$ & PSQI & $\begin{array}{l}202 \text { Ps patients } \\
\text { vs. } 202 \text { controls }\end{array}$ & $\begin{array}{l}\text { PSQI mean score: Ps patients } 5.56 \pm 3.93 \text { points, controls } \\
5.13 \pm 4.16 \text { points }\end{array}$ \\
\hline $\begin{array}{l}\text { Mrowietz } \\
\text { et al., } 2014 \\
{[56]}\end{array}$ & Clinical trial & $\begin{array}{l}\text { MOS-SS } \\
\text { SPI II }\end{array}$ & 270 Ps patients & $\begin{array}{l}\text { MOS-SS scores: } \\
\text { 1. SPI II mean score: } \\
\text { - No itch } 22.17 \pm 18.17 \text { points, } \\
\text { - Mild-to-moderate itch } 29.60 \pm 15.86 \text { points, } \\
\text { Severe itch } 37.52 \pm 19.86 \text { points. } \\
\text { MOS-SS scores were significantly associated with itch. } \\
\text { Etanercept treatment significantly improved quality of sleep in } \\
\text { patients with clinically meaningful improvement in itch versus } \\
\text { with no clinically meaningful improvement in itch }\end{array}$ \\
\hline $\begin{array}{l}\text { Thaci et al., } \\
2014[55]\end{array}$ & Clinical trial & $\begin{array}{l}\text { MOS-SS } \\
\text { SPI II }\end{array}$ & 270 Ps patients & $\begin{array}{l}\text { MOS-SS mean score: SPI II mean score } 34.0 \text { points. } \\
\text { Etanercept treatment significantly improved quality of sleep. } \\
\text { Sleep improvement was associated with improved QoL }\end{array}$ \\
\hline $\begin{array}{l}\text { Balta et al., } \\
2016[50]\end{array}$ & $\begin{array}{l}\text { Case-control } \\
\text { study }\end{array}$ & PSQI & $\begin{array}{l}37 \text { Ps patients } \\
\text { vs. } 42 \text { controls }\end{array}$ & $\begin{array}{l}\text { PSQI mean score - data not shown. } \\
\text { The PSQI subscales for subjective sleep quality and habitual } \\
\text { sleep efficiency ( } p=0.04 \text { and } p=0.01 \text {, respectively) }\end{array}$ \\
\hline $\begin{array}{l}\text { Luca et al., } \\
2016[51]\end{array}$ & $\begin{array}{l}\text { Uncontrolled } \\
\text { clinical study }\end{array}$ & PSQI & 102 Ps patients & PSQI mean score $4.4 \pm 3.6$ points \\
\hline $\begin{array}{l}\text { Henry et al. } \\
2017[52]\end{array}$ & $\begin{array}{l}\text { Uncontrolled } \\
\text { clinical study }\end{array}$ & PSQI & 186 Ps patients & PSQI mean score: $9.2 \pm 4.3$ points \\
\hline $\begin{array}{l}\text { Melikoglu, } \\
2017 \text { [53] }\end{array}$ & $\begin{array}{l}\text { Case-control } \\
\text { study }\end{array}$ & PSQI & $\begin{array}{l}58 \text { Ps patients } \\
\text { vs. } 58 \text { controls }\end{array}$ & $\begin{array}{l}\text { PSQI mean score: Ps patients } 7.01 \pm 4.19 \text { points, controls } \\
4.18 \pm 2.76 \text { points }(p<0.0001) \text {. } \\
\text { PSQI and PASI were significantly correlated }(p=0.03)\end{array}$ \\
\hline $\begin{array}{l}\text { Jensen et al., } \\
2018[54]\end{array}$ & $\begin{array}{l}\text { Case-control } \\
\text { study }\end{array}$ & PSQI & $\begin{array}{l}179 \text { Ps patients } \\
\text { vs. } 105 \text { controls }\end{array}$ & $\begin{array}{l}\text { PSQI mean score: Ps patients } 6.5 \pm 3.5 \text { points, controls } \\
4.2 \pm 2.4 \text { points }(p<0.0001)\end{array}$ \\
\hline $\begin{array}{l}\text { Kaaz et al., } \\
2018 \text { [44] }\end{array}$ & $\begin{array}{c}\text { Case-control } \\
\text { study }\end{array}$ & PSQI & $\begin{array}{l}100 \text { Ps patients } \\
\text { vs. } 50 \text { controls }\end{array}$ & $\begin{array}{l}\text { PSQI mean score: Ps patients } 8.1 \pm 4.8 \text { points, controls } \\
3.1 \pm 1.9 \text { points }(p<0.0001) \text {. } \\
\text { The severity of itch was significantly correlated with PSQI } \\
\text { scores }(r=0.59, p<0.001)\end{array}$ \\
\hline $\begin{array}{l}\text { Pappadavid } \\
\text { et al., } 2013 \\
{[57]}\end{array}$ & $\begin{array}{l}\text { Uncontrolled } \\
\text { clinical study }\end{array}$ & Polysomnography & 35 Ps patients & $\begin{array}{l}\text { Ps patients with obstructive sleep apnea and hypopnea } \\
\text { syndrome (OSAHS) presented more frequent snoring and } \\
\text { lower sleep quality compared with those without OSAHS. } \\
\text { OSAHS may be a comorbidity in obese psoriasis patients with } \\
\text { hypertension }\end{array}$ \\
\hline
\end{tabular}

dysfunction [53] and sleep latency, sleep duration, sleep disturbances and use of sleeping medication domains [44] was established. Moreover, habitual sleep efficiency was significantly impaired in three studies [44, 50, 53]. PSQI scores were significantly correlated with severity of psoriasis assessed by the Psoriasis Area and Severity Index (PASI) $(p=0.03)$ [53] and itch severity $(p<0.001)$ [44]. The MOS-SS questionnaire was used in three studies, revealing comparable results [36, 48, 55]. Furthermore, Mrowietz et al. [56] reported that Ps patients complaining of severe itch were more prone to develop sleep impairment evaluated by mean MOS-SS score $(p<0.001)$. Psoriasisrelated itch seems to play a substantial role in impairing sleep quality of Ps patients $[44,56]$. The study based on polysomnography presented similar sleep structure with similar total sleep time and somnolence score among Ps patients with and without OSAHS [57]. Nonetheless, worse sleep quality and increased snoring frequency in Ps patients with OSAHS compared to Ps patients without OSAHS were revealed [57]. Furthermore, Pappadavid et al. 
[57] suggested that OSAHS may be a comorbidity in overweight Ps patients with hypertension, making this combination particularly unfavorable in the terms of sleep quality. Additionally, it was confirmed that adalimumab and etanercept treatment significantly improved sleep quality among Ps patients $[36,55,56]$. Detailed characteristics are shown in Table 2.

\section{Prurigo nodularis}

Prurigo nodularis (PN) is a chronic skin condition of still unknown etiology. The PN is characterized by firm nodules, mostly localized symmetrically over the extensor surfaces of the lower extremities. Skin lesions are either primary or secondary to repeated traumatic manipulation due to chronic itch [58]. The PN is associated with a significant burden of disease, contributing to mood disorders and disrupting sleep quality [59]. Konda et al. [21] suggested that PN, itching, sleep disturbance and depression may be interrelated symptoms with the same underlying mechanism in the form of immune system activation and lower serum serotonin. In a case-control study among 39 PN patients and 39 controls, PSQI mean scores were assessed as $5.59 \pm 3.73$ points and $4.46 \pm 2.82$ points, respectively [21]. Moreover, sleep quality in PN patients assessed by PSQI significantly correlated with the outcomes of the 17-item version of the Hamilton Depression Rating Scale (HDRS-17) $(r=0.635, p<0.01)$ [21]. Nonetheless, the quality of sleep did not correlate with itch severity [21].

\section{Chronic spontaneous urticaria}

Chronic spontaneous urticaria (CSU) is defined by the spontaneous appearance of wheals with or without edema that persist for more than 6 weeks [60]. The mean disease prevalence is estimated up to $1 \%$ of the general population [61]. The CSU can be very distressing and may severely impair the QoL [62]. Sleep quality estimated with the PSQI questionnaire among CSU patients (mean PSQI score: 4.5 points) was significantly impaired when compared to the controls (mean PSQI score: 4.0 points) $(p<0.001)$ [20]. Additionally, the severity of urticarial symptoms assessed with the Urticaria Activity Score over 7 days (UAS-7) significantly correlated with decreased sleep quality (i.e. PSQI scores) ( $p=0.00001$ ) [20]. Furthermore, a study by Abdel Latif showed a significant influence on sleep latency, sleep duration, sleep disturbance and daytime dysfunction domains [20]. Gimenéz-Arnau et al. [63], reporting the results of three randomized, double-blind, placebo-controlled studies, found a substantial improvement of sleep quality assessed by MOS-SS SPI-II under omalizumab treatment.

\section{Hidradenitis suppurativa}

Hidradenitis suppurativa (HS) is a chronic, recurrent, inflammatory, suppurative and debilitating disease of the hair follicle manifested by painful abscesses, fistulas and scarring lesions in the apocrine gland-bearing areas of the body, mostly the axillae, inguinal and anogenital regions [64]. The disease affects up to $1 \%$ of the general population with female predominance $[65,66]$. The HS-related QoL impairment includes an impact on multiple aspects of psychophysical functioning and well-being in affected patients, resulting in decreased overall activity, depression, anxiety, fatigue and stigmatization [67, 68]. A casecontrol study, involving 108 HS patients and 50 controls, established a significantly decreased sleep quality among HS sufferers compared to controls (PSQI mean scores assessed as $6.5 \pm 3.6$ points and $3.1 \pm 1.9$ points, respectively $(p<0.0001))$ [22]. Additionally, significant influences on sleep latency, sleep duration and sleep disturbance were revealed [22]. Of note, pain seems to play a crucial role in impairing sleep quality of HS patients [22].

\section{Discussion}

Chronic skin diseases, such as atopic dermatitis, psoriasis, prurigo nodularis, chronic urticaria and hidradenitis suppurativa, have a great impact on health-related QoL of affected individuals [40, 59, 62, 67-69]. Skin plays an important role in proper sleep physiology. Itch, pain, mood, cognitive and somatic arousal or anxiety were established as having a potential impact on sleep quality $[18,52]$. The negative influence of itch on the quality of sleep was revealed in patients with chronic inflammatory dermatoses such as AD and Ps [70-72]. This study was undertaken to examine sleep quality in patients with chronic skin diseases, with a particular focus on atopic dermatitis, plaque psoriasis, prurigo nodularis, chronic urticarial and hidradenitis suppurativa. In available studies the quality of sleep was assessed by objective and/or subjective methods.

In atopic dermatitis patients the mean total PSQI scores ranged from 7.0 to 8.5 points (Table 1) [37, 41, 42, 44]. Affected sleep quality significantly correlated with reduced QoL [37, 41]. Furthermore, subjective sleep quality and daytime dysfunction were found to be the most affected parameters in $A D$ patients as compared to the controls [42]. Nonetheless, a previously published study revealed that all PSQI domains were significantly affected in AD patients [44]. Poor sleep quality assessed by PSQI significantly correlated with AD severity estimated with SCORing of Atopic Dermatitis (SCORAD) [41]. The $A D$ patients with more severe disease assessed with Investigator Global Assessment (IGA) and the Eczema Area and Severity Index (EASI) had worse sleep measured by actigraphy, as was demonstrated by the marker of sleep disruption wake after sleep onset (WASO) [38]. Moreover, the perception of itch assessed by actigraphy increased with poor efficiency of sleep and more minutes awake [42]. Furthermore, investigators suggested that the number of awakenings and increasing number of minutes awake are associated with increased itch and impaired 
QoL [42]. A study by Bender et al. [43] revealed moderately strong correlations between actigraphy scores and both the scratching index and PSG scores, which included sleep latency, sleep efficiency and stage-2 sleep. Furthermore, they found that sleep quality decreases as the severity of AD increases [43] and suggested that objective measures (actigraphy and polysomnography), contrary to self-reported questionnaires, are more useful to demonstrate that the increased $A D$ severity results in the impairment of sleep quality and more scratching [43]

In psoriasis patients PSQI mean scores were assessed as 4.4-9.2 points (Table 2) [44, 48, 49, 52, 53]. The Ps significantly affected subjective sleep quality, daytime dysfunction and habitual sleep efficiency as compared to the controls $[50,53]$. A recently published study showed a significant impact of Ps on sleep latency, sleep duration, habitual sleep efficiency, sleep disturbances and use of sleeping medication [44]. In a study published by Melikoglu a significant association between global PSQI score and Ps severity assessed by PASI was established [53]. Balta et al. [50] suggested that poor sleep quality may be associated with the itch and pain caused by Pslinked skin lesions. Nonetheless, only itch severity, but not pain, significantly correlated with PSQI total score [44]. Furthermore, it was found that improved psoriasis control with itch reduction may increase sleep quality of affected patients [54]. The Ps patients with moderateto-severe disease have impaired sleep quality, which is linked to poor QoL [55]. Moreover, Shutty et al. [48] suggested that sleep disturbances associated with Ps may be secondary to depression rather than related to a Ps direct effect. The obstructive sleep apnea and hypopnea syndrome (OSAHS), which may be a comorbidity in obese psoriasis patients with hypertension, was indicated as a potential predictor of poor sleep quality [57]. It was also noted that sleep quality in Ps patients on adalimumab or etanercept treatment was improved $[36,55,56]$.

In prurigo nodularis patients the mean PSQI score was 5.59 points [21]. Konda et al. [21] established no significant correlation between the severity of itch and depression severity or sleep quality. Nonetheless, a significant correlation between sleep quality and depression in PN patients was found $(r=0.635, p<0.01)$.

In chronic spontaneous urticaria patients PSQI mean score was 4.5 points - a significantly higher result as compared to the controls ( $p<0.001$ ) [20]. Furthermore, increased severity of the urticaria symptoms assessed by UAS-7 correlated with poor sleep quality (PSQI mean score). Moreover, it was demonstrated that such parameters as sleep duration, sleep disturbance, sleep latency and day dysfunction due to sleepiness in CSU patients were significantly affected, as compared to the controls [20]. Gimenéz-Arnau et al. [63] established sleep improvement among CSU patients receiving omalizumab.

In hidradenitis suppurativa patients the mean PSQI score was assessed as 6.5 points and was significantly higher than in the control group $(p<0.0001)$ [22]. Sleep latency, sleep duration, habitual sleep efficiency, sleep disturbances and daytime dysfunction were also significantly affected in HS patients, as compared to the controls. Moreover, pain seems to be a crucial factor affecting the sleep quality of HS patients.

Zachariae et al. [73] suggested that itch-related sleep impairment could be a significant partial mediator of the relationship between somatic and psychological symptoms and the severity of itch. It is recommended that clinicians ask patients about the current sleep quality during a routine evaluation of the clinical severity of a chronic skin disease and request further consultations when necessary. Polysomnography and actigraphy should be performed for the objective assessment of sleep quality. Nonetheless, a questionnaire-based evaluation of sleep quality is more useful in clinical practice and clinical studies. Moreover, further immunologic or neurologic clinical studies are necessary to investigate the relationship between chronic skin diseases and sleep disorders.

In conclusion, subjective symptoms such as itch and pain have a substantial impact on sleep quality and general quality of life in patients with chronic skin diseases.

Moreover, further investigation into objective measurements of the quality of sleep, such as long-term questionnaire-based epidemiological studies, is necessary to understand the nature and exact mechanism of poor sleep among sufferers with chronic skin diseases. Therefore, reliable guidelines concerning the evaluation and management of sleep disorders in chronic dermatological patients should be provided. Furthermore, the management of sleep disturbance in patients with chronic dermatoses should focus on effective disease control with strategies for itch and pain relief as well as on possible medical interventions to help improve sleep.

\section{Acknowledgments}

Research grant by Wroclaw Medical University (grant No. STM.C260.16.030).

\section{Conflict of interest}

The authors declare no conflict of interest.

\section{References}

1. Leung DY, Guttman-Yassky E. Deciphering the complexities of atopic dermatitis: shifting paradigms in treatment approaches. J Allergy Clin Immunol 2014; 134: 769-79.

2. Gupta MA, Gupta AK. Sleep-wake disorders and dermatology. Clin Dermatol 2013; 31: 118-26.

3. Lavery MJ, Stull C, Kinney MO, et al. Nocturnal pruritus: the battle for a peaceful night's sleep. Int J Mol Sci 2016; 17: 425.

4. Aras YG, Tunç A, Güngen BD, et al. The effects of depression, anxiety and sleep disturbances on cognitive impairment in patients with chronic obstructive pulmonary disease. Cogn Neurodyn 2017; 11: 565-71. 
5. Bacci MR, Emboz JN, Alves BD, et al. Obstructive sleep apnea syndrome and sleep quality in hypertensive patients. Rev Assoc Med Bras 2017; 63: 1055-60.

6. Garcia S, Alosco ML, Spitznagel MB, et al. Poor sleep quality and reduced cognitive function in persons with heart failure. Int J Cardiol 2012; 156: 248-9.

7. Zuurbier LA, Luik Al, Leening MJ, et al. Associations of heart failure with sleep quality: the Rotterdam Study. J Clin Sleep Med 2015; 11: 117-21.

8. Akman T, Yavuzsen T, Sevgen Z, et al. Evaluation of sleep disorders in cancer patients based on Pittsburgh Sleep Quality Index. Eur J Cancer Care 2015; 24: 553-9.

9. Nishiura M, Tamura A, Nagai H, et al. Assessment of sleep disturbance in lung cancer patients: relationship between sleep disturbance and pain, fatigue, quality of life, and psychological distress. Palliat Support Care 2015; 13: 575-81.

10. Redeker NS, Pigeon WR, Boudreau EA. Incorporating measures of sleep quality into cancer studies. Support Care Cancer 2015; 23: 1145-55.

11. Chen D, Yin Z, Fang B. Measurements and status of sleep quality in patients with cancers. Support Care Cancer 2018; 26: 405-14.

12. Hammersen F, Lewin P, Gebauer J, et al. Sleep quality and healthrelated quality of life among long-term survivors of (non-)Hodgkin lymphoma in Germany. PLoS One 2017; 12: e0187673.

13. Margiotta DPE, Basta F, Dolcini G, et al. The relation between, metabolic syndrome and quality of life in patients with systemic lupus erythematosus. PLoS One 2017; 12: e0187645.

14. Zhao Q, Deng N, Chen S, et al. Systemic lupus erythematosus is associated with negatively variable impacts on domains of sleep disturbances: a systematic review and meta-analysis. Psychol Health Med 2018; 23: 685-97.

15. Gezer O, Batmaz I, Sariyildiz MA, et al. Sleep quality in patients with psoriatic arthritis. Int J Rheum Dis 2017; 20: 1212-8.

16. Bosse-Henck A, Wirtz H, Hinz A. Subjective sleep quality in sarcoidosis. Sleep Med 2015; 16: 570-6.

17. Jeon C, Yan D, Nakamura M, et al. Frequency and management of sleep disturbance in adults with atopic dermatitis: a systematic review. Dermatol Ther (Heidelb) 2017; 7: 34964.

18. Henry AL, Kyle SD, Bhandari S, et al. Measurement, classification and evaluation of sleep disturbance in psoriasis: a systematic review. PLoS One 2016 21; 11: e0157843.

19. Gupta MA, Simpson FC, Gupta AK. Psoriasis and sleep dis orders: a systematic review. Sleep Med Rev 2016; 29: 63-75.

20.Abdel Latif OM. Impact of severity of CSU on sleep, anxiety and depressive symptoms in adults. Eur Acad Res 2017; 2 1145-57.

21. Konda D, Chandrashekara L, Rajappab M, et al. Serotonin and interleukin-6: association with pruritus severity, sleep quality and depression severity in prurigo nodularis. Asian J Psychiatr 2015; 17: 24-8.

22. Kaaz K, Szepietowski JC, Matusiak Ł. Influence of itch and pain on sleep quality in patients with hidradenitis suppurativa. Acta Derm Venereol 2018; 98: 757-61.

23. Albuquerque RG, da Rocha MA, Hirotsu C, et al. A randomized comparative trial of a combined oral contraceptive and azelaic acid to assess their effect on sleep quality in adult female acne patients. Arch Dermatol Res 2015; 307: 905-15.

24. Adamo D, Ruoppo E, Leuci S, et al. Sleep disturbances, anxiety and depression in patients with oral lichen planus: a casecontrol study. J Eur Acad Dermatol Venereol 2015; 29: 291-9.
25. Yosipovitch G, Xiong GL, Haus E, et al. Time-dependent variations of the skin barrier function in humans: transepidermal water loss, stratum corneum hydration, skin surface $\mathrm{pH}$, and skin temperature. J Invest Dermatol 1998; 110: 20-3.

26. Benca R. Sleep Disorders: The Clinician's Guide to Diagnosis and Management. Oxford University Press, Oxford 2012.

27. Thorburn PT, Riha RL. Skin disorders and sleep in adults: where is the evidence? Sleep Med Rev 2010; 14: 351-8.

28. Schwarz W, Birau N, Hornstein OP, et al. Alterations of melatonin secretion in atopic eczema. Acta Derm Venereol 1988; 68: 224-9.

29. Patel T, Ishiuji Y, Yosipovitch G. Nocturnal itch: why do we itch at night? Acta Derm Venereol 2007; 87: 295-8.

30. Buysse DJ, Reynolds CF 3rd, Monk TH, et al. The Pittsburgh sleep quality index: a new instrument for psychiatric practice and research. Psychiatry Res 1989; 28: 193-213.

31. Mollayeva T, Thurairajah P, Burton K, et al. The Pittsburgh sleep quality index as a screening tool for sleep dysfunction in clinical and non-clinical samples: a systematic review and meta-analysis. Sleep Med Rev 2016; 25: 52-73.

32. Buysse DJ, Reynolds CF 3rd, Monk TH, et al. The Pittsburgh sleep quality index. University of Pittsburgh using National Institute of Mental Health Funding 1989.

33. Hays RD, Martin SA, Sesti AM, et al. Psychometric properties of the Medical Outcomes Study Sleep measure. Sleep Med 2005; 6: 41-4

34. Rejas J, Ribera MV, Ruiz M, et al. Psychometric properties of the MOS (Medical Outcomes Study) Sleep Scale in patients with neuropathic pain. Eur J Pain 2007; 11: 329-40.

35. Hays R D, Stewart AL. Sleep measures. In: Measuring Functioning and Well-being: The Medical Outcomes Study Approach. Stewart AL, Ware JE (eds.). Duke University Press, Durham 1992; 235-59.

36. Strober BE, Sobell JM, Duffin KC, et al. Sleep quality and other patient-reported outcomes improve after patients with psoriasis with suboptimal response to other systemic therapies are switched to adalimumab: results from PROGRESS, an open-label phase IIIB trial. Br J Dermatol 2012; 167: 1374-81.

37. Kong TS, Han TY, Lee JH, et al. Correlation between severity of atopic dermatitis and sleep quality in children and adults. Ann Dermatol 2016; 28: 321-6.

38. Sandoval LF, Huang K, O'Neill JL, et al. Measure of atopic dermatitis disease severity using actigraphy. J Cutan Med Surg 2014; 18: 49-55.

39. Barbarot S, Auziere S, Gadkari A, et al. Epidemiology of atopic dermatitis in adults: results from an international survey. Allergy 2018; 73: 1284-93.

40.Chrostowska-Plak D, Reich A, Szepietowski JC. Relationship between itch and psychological status of patients with atopic dermatitis. J Eur Acad Dermatol Venereol 2013; 27: 239-42.

41. Yano C, Saeki H, Ishiji T, et al. Impact of disease severity on sleep quality in Japanese patients with atopic dermatitis. J Dermatol Sci 2013; 72: 195-7.

42. Bender BG, Leung SB, Leung DY. Actigraphy assessment of sleep disturbance in patients with atopic dermatitis: an objective life quality measure. J Allergy Clin Immunol 2003; 111: 598-602.

43. Bender BG, Ballard R, Canono B, et al. Disease severity, scratching, and sleep quality in patients with atopic dermatitis. J Am Acad Dermatol 2008; 58: 415-20.

44. Kaaz K, Szepietowski JC, Matusiak $Ł$. Influence of itch and pain on sleep quality in atopic dermatitis and psoriasis. Acta Derm Venereol 2019; 99: 175-80. 
45. Bringhurst C, Waterston K, Schofield O, et al. Measurement of itch using actigraphy in pediatric and adult populations. J Am Acad Dermatol 2004; 51: 893-8.

46. Parisi R, Symmons DP, Griffiths CE, et al. Identification and management of psoriasis and associated comorbidity (IMPACT) project team. Global epidemiology of psoriasis: a systematic review of incidence and prevalence. J Invest Dermatol 2013; 133: 377-85.

47. Griffiths CE, Barker JN. Pathogenesis and clinical features of psoriasis. Lancet 2007; 21: 370: 263-71.

48. Shutty BG, West C, Huang KE, et al. Sleep disturbances in psoriasis. Dermatol Online J 2013; 19: 1

49. Stinco G, Trevisan G, Piccirillo F, et al. Psoriasis vulgaris does not adversely influence the quality of sleep. G Ital Dermato Venereol 2013; 148: 655-9.

50. Balta I, Karadag AS, Selek S, et al. General psychiatric symptoms, quality of sleep, and coping strategies in patients with psoriasis vulgaris. Int J Dermatol 2016; 55: 60-4.

51. Luca M, Luca A, Musumeci ML, et al. Psychopathological variables and sleep quality in psoriatic patients. Int J Mol Sci 2016; 17: 1184.

52. Henry AL, Kyle SD, Chisholm A, et al. A cross-sectional survey of the nature and correlates of sleep disturbance in people with psoriasis. Br I Dermatol 2017; 177: 1052-9.

53. Melikoglu M. Sleep quality and its association with disease severity in psoriasis. Eurasian J Med 2017; 49: 124-7.

54. Jensen $P$, Zachariae C, Skov L, et al. Sleep disturbance in psoriasis - a case-controlled study. Br J Dermatol 2018; 179: 1376-84.

55. Thaçi D, Galimberti R, Amaya-Guerra M, et al. Improvement in aspects of sleep with etanercept and optional adjunctive topical therapy in patients with moderate-to-severe psoriasis: results from the PRISTINE trial. J Eur Acad Dermato Venereol 2014; 28: 900-6.

56. Mrowietz U, Chouela EN, Mallbris L, et al. Pruritus and quality of life in moderate-to-severe plaque psoriasis: post hoc explorative analysis from the PRISTINE study. J Eur Acad Dermatol Venereol 2015; 29: 1114-20.

57. Papadavid E, Vlami K, Dalamaga M, et al. Sleep apnea as a comorbidity in obese psoriasis patients: a cross-sectional study. Do psoriasis characteristics and metabolic parameters play a role? J Eur Acad Dermatol Venereol 2013; 27: 820-6.

58. Vaidya DC, Schwartz RA. Prurigo nodularis: a benign dermatosis derived from a persistent pruritus. Acta Dermatovenerol Croat 2008; 16: 38-44.

59. Boozalis E, Tang O, Patel S, et al. Ethnic differences and comorbidities of 909 prurigo nodularis patients. J Am Acad Dermatol 2018; 79: 714-9.

60.Zuberbier T, Aberer W, Asero R, et al. The EAACI/GA2LEN/ EDF/WAO guideline for the definition, classification, diagnosis and management of urticarial. Allergy 2018; 73: 1393-414.

61. Saini SS. Chronic spontaneous urticaria: etiology and pathogenesis. Immunol Allergy Clin North Am 2014; 34: 33-52.

62. Weldon DR. Quality of life in patients with urticaria. Allergy Asthma Proc 2006; 27: 96-9.

63. Gimenéz-Arnau M, Spector S, Antonova E, et al. Improvement of sleep in patients with chronic idiopathic/spontaneous urticaria treated with omalizumab: results of three randomized, double-blind, placebo-controlled studies Ana Clin Transl Allergy 2016; 6: 32.

64.Zouboulis CC, Desai N, Emtestam L, et al. European S1 guideline for treatment of hidradenitis suppurativa/acne inversa. J Eur Acad Dermatol Venereol 2015; 29: 619-44.
65.Jemec GB, Heidenheim M, Nielsen NH. The prevalence of hidradenitis suppurativa and its potential precursor lesions. J Am Acad Dermatol 1996; 35: 191-4.

66. Revuz JE, Canoui-Poitrine F, Wolkenstein P, et al. Prevalence and factors associated with hidradenitis suppurativa: results from two case-control studies. J Am Acad Dermatol 2008; 59: 596-601.

67. Matusiak Ł, Bieniek A, Szepietowski JC. Hidradenitis suppurativa markedly decreases quality of life and professional activity. J Am Acad Dermatol 2010; 62: 706-8.

68. Matusiak $Ł$, Bieniek A, Szepietowski JC. Psychophysical aspects of hidradenitis suppurativa. Acta Derm Venereol 2010; 90: 264-8.

69. Reich A, Hrehorów E, Szepietowski JC. Pruritus is an important factor negatively influencing the well-being of psoriatic patients. Acta Derm Venereol 2010; 90: 257-63.

70. Chang YS, Chou YT, Lee JH, et al. Atopic dermatitis, melatonin, and sleep disturbance. Pediatrics 2014; 134: 397-405.

71. Yu SH, Attarian H, Zee P, et al. Burden of sleep and fatigue in US adults with atopic dermatitis. Dermatitis 2016; 27: 50-8.

72. O'Neill JL, Chan YH, Rapp SR, et al. Differences in itch characteristics between psoriasis and atopic dermatitis patients: results of a web-based questionnaire. Acta Derm Venereol 2011; 91: 537-40.

73.Zachariae R, Lei U, Haedersdal M, et al. Itch severity and quality of life in patients with pruritus: preliminary validity of a Danish adaptation of the itch severity scale. Acta Derm Venereol 2012; 92: 508-14. 